\title{
Hallazgo de Dioctophyme renale en la cavidad torácica de un canino
}

\author{
Meyer, S.N.'; Rosso, M. ${ }^{2}$; Maza, Y.E. ${ }^{1}$
}

${ }^{1}$ Cátedra Enfermedades Parasitarias, Facultad de Ciencias Veterinarias, UNNE, Sargento Cabral 2139,

Corrientes (3400), Argentina. Tel. 03794425753 int. 141. E-mail: parasito@vet.unne.edu.ar.

${ }^{2}$ Actividad privada en diagnóstico histopatológico, Resistencia (Argentina).

E-mail: histopatologiaveterinariachaco@yahoo.com.ar.

\begin{abstract}
Resumen
Meyer, S.N.; Rosso, M.; Maza, Y.E.: Hallazgo de Dioctophyme renale en la cavidad torácica de un canino. Rev. vet. 24: 1, 63-65, 2013. El estadio adulto del nematode Dioctophyme renale habitualmente parasita el riñón derecho del perro y de varios mamíferos domésticos y silvestres, aunque a veces aparece en otros órganos o tejidos. El propósito de este trabajo fue reportar el hallazgo de ejemplares adultos y huevos de $D$. renale en las cavidades corporales de un canino hembra, de raza indefinida y 18 meses de edad. El animal fue hallado sin vida por el propietario, quien solicitó la realización de una necropsia para descartar o confirmar un posible envenenamiento. La necropsia reveló la presencia de dos ejemplares adultos del parásito, uno en la cavidad abdominal y otro en la cavidad torácica. Este último medía 40 $\mathrm{cm}$ de longitud x $10 \mathrm{~mm}$ de diámetro. En la pleura mediastínica se verificó la existencia de 12 orificios de 20 a $50 \mathrm{~mm}$ de diámetro. Los pulmones mostraban lesiones focales que resultaron más numerosas en el lóbulo medio derecho que en el resto de los lóbulos; los cortes histológicos revelaron la presencia de abundantes estructuras compatibles con huevos de $D$. renale en la superficie pleural, donde también se constataron varias áreas con intensa respuesta inflamatoria. Los hallazgos histopatológicos caracterizaron la existencia de una pleuritis granulomatosa multifocal.
\end{abstract}

Palabras clave: perro, Dioctophyme renale, cavidad torácica, pleuritis granulomatosa.

\begin{abstract}
Meyer, S.N.; Rosso, M.; Maza, Y.E.: Finding of Dioctophyme renale in the thoracic cavity of a dog. Rev. vet. 24: 1, 63-65, 2013. The adult stage of Dioctophyme renale usually parasites the right kidney of dogs and other wild and domestic mammals, although it may affect other organs or tissues as well. The purpose of this study was to report the finding of adults and eggs of $D$. renale in body cavities of a female dog, 18 months-old. The animal was found dead by the owner, who later asked for a necropsy at the School of Veterinary Science, Universidad Nacional del Nordeste, Corrientes, Argentina, as a poisoning was suspected as cause of death. Necropsy revealed the presence of two adult worms, one in the abdominal cavity and the other in the thorax, the latter measuring $40 \mathrm{~cm}$ long and $10 \mathrm{~mm}$ in diameter. In the mediastinal pleura it was verified the presence of 12 perforations, 20 to $50 \mathrm{~mm}$ in diameter. The lungs showed focal lesions, being more numerous in the right middle lobe. Histological sections revealed numerous eggs of $D$. renale. Histopathological findings characterized the existence of a multifocal granulomatous pleuritis.
\end{abstract}

Key words: dog, Dioctophyme renale, thoracic cavity, parasitary pleuritis.

\section{INTRODUCCIÓN}

La dioctofimosis es una helmintiasis causada por Dioctophyme renale (Goeze, 1782), nematode conocido como "gusano gigante del riñón" que afecta a diversos mamíferos domésticos y silvestres, capaz de parasitar al ser humano como huésped accidental ${ }^{7}$. Su ciclo vital es largo y complejo; en estadio adulto se encuentra habitualmente en el riñón derecho, a veces se halla libre

Recibido: 28 febrero 2013 / Aceptado: 30 abril 2013 en las cavidades peritoneal o pleural y otras veces en hígado u otros tejidos ${ }^{4}$.

En el huésped definitivo los huevos son eliminados con la orina y requieren un medio acuático para ser ingeridos por el huésped intermediario, en el cual continúan su desarrollo hasta el estadio infestante (larva 3). Cuando el huésped definitivo ingiere al intermediario, el parásito evoluciona al estadio adulto en su interior. Ranas y peces pueden participar en el ciclo como hospedadores paraténicos cuando se alimentan con los huéspedes intermediarios. Los paraténicos no 
son esenciales en el ciclo pero contribuyen al mantenimiento del parásito en la naturaleza ${ }^{1,2,8}$.

En el nordeste argentino, D. renale fue hallado por primera vez en 1979 en riñón derecho de perros oriundos de los alrededores de Resistencia (Chaco) ${ }^{3}$. Más tarde, en 1986 fue reportado en canes de la ciudad de Formosa ${ }^{5}$ y en 1989 se denunció su existencia en las localidades chaqueñas de Barranqueras y Puerto Vilelas ${ }^{6}$.

El propósito de esta comunicación breve fue reportar el hallazgo de un ejemplar adulto, así como huevos de $D$. renale, en cavidad torácica de un canino de la ciudad de Resistencia. Se detallan las lesiones histopatológicas provocadas por el parásito en cavidad torácica y en pulmones.

\section{MATERIAL Y MÉTODOS}

El cadáver reciente de una perra de un año y medio de edad y raza indefinida fue llevado al consultorio por su propietario ante la sospecha de envenenamiento, dado que previamente a la muerte no se advirtieron signos de enfermedad. Se realizó una necropsia completa, prestando preferencial atención a las cavidades toráci-

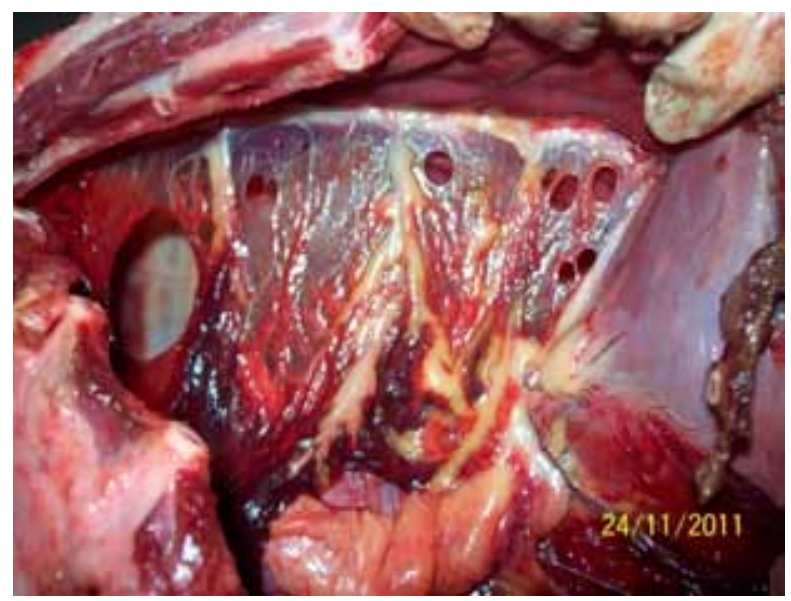

Figura 1. Pleura mediastínica con numerosos orificios producidos por el pasaje de ejemplares adultos de $D$. renale.

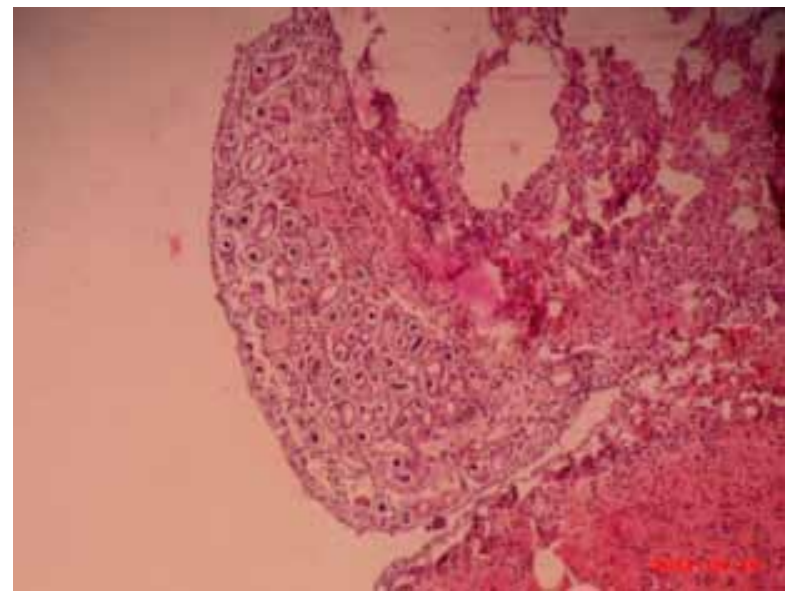

Figura 2. Pleuritis granulomatosa. Nótese abundante cantidad de huevos de D. renale. ca y abdominal. El material extraído para histopatología fue procesado por la técnica de bloques parafinados y coloreado con hematoxilina-eosina para ser examinado mediante microscopía óptica.

\section{RESULTADOS Y DISCUSIÓN}

En el examen externo se constató presencia de rigor mortis, sin lesiones aparentes en piel ni aberturas naturales. Tampoco se verificaron lesiones en tejidos subcutáneo, adiposo, muscular, nódulos linfáticos, huesos, articulaciones, cavidad bucal, faringe, esófago, estómago, hígado, páncreas, intestinos delgado y grueso, fosas nasales, laringe y tráquea. Los sistemas reproductivo, hematopoyético y nervioso no revelaron daños aparentes. En la cavidad pelviana los riñones estaban ligeramente agrandados, blandos y edematosos. Uréteres, vejiga y uretra estaban congestivos. Arterias, venas y vasos linfáticos revelaron la presencia de petequias aisladas, sin coágulos.

En la cavidad abdominal se comprobó la presencia de un ejemplar adulto de $D$. renale de $20 \mathrm{~cm}$ de longitud x $5 \mathrm{~mm}$ de diámetro, libre, en cercanías del diafragma. Por su parte, en la cavidad torácica se evidenció otro parásito adulto de la misma especie, de $40 \mathrm{~cm} \mathrm{x}$ $10 \mathrm{~mm}$, de color rojo vinoso. En la pleura mediastinal se observaron 12 orificios cuyos diámetros oscilaron entre 20 y $50 \mathrm{~mm}$ (Figura 1), algunos con un halo congestivo periférico. En la superficie de los pulmones se registraron lesiones focales más claras en el lóbulo medio derecho y otras aisladas en los demás lóbulos. En las áreas pleurales afectadas, el análisis histopatológico reveló una intensa respuesta inflamatoria en derredor a los huevos de $D$. renale (Figura 2).

Los hallazgos anatomohistopatológicos indicaron la presencia de una pleuritis granulomatosa multifocal ${ }^{9}$, seguramente causada por la presencia de gran cantidad de huevos de $D$. renale. La reacción inflamatoria estaba compuesta principalmente por macrófagos y eosinófilos. La perforación de la pleura del mediastino probablemente pueda ser atribuible a la acción del parásito adulto que deambulaba libre en la cavidad torácica.

Se confirma una vez más la gran ubicuidad de este nematode hologonio, facultad que le permite desarrollarse y efectuar oviposición en las más recónditas zonas del organismo ${ }^{1,2}$, así como la gravedad de las lesiones que es capaz de inducir ${ }^{3,8}$. Esta muerte asintomática enfatiza que en medicina veterinaria es imperativo recurrir a todas las técnicas disponibles para lograr un diagnóstico acertado.

\section{REFERENCIAS}

1. Acha P, Zsyfres B. 2003. Zoonosis y enfermedades transmisibles comunes al hombre y a los animales, Publ. OPS, Washington, p. 806-809.

2. Basso N, Calzetta E, Duguetti R, Giménez R, Perez Tort G, Rosa A, Welch E. 1987. Fundamentos de parasitología veterinaria, Hemisferio Sur, Buenos Aires, p. 92-94. 
3. Coppo JA, Brem JJ. 1983. Canine dioctophymosis in the north east of Argentina. Med Trop 25: 259-262.

4. Kano FS, Shimada MT, Suzuki SN. 2003. Ocorrência da dioctofimose em dois cães no município de Guarapuava (Brasil). Ciências Agrárias 24: 177-180.

5. Mancebo OA, Roux JP. 1986. Dioctofimosis canina en Formosa. Comunicación previa. Vet Arg 3: 227-228.

6. Moriena RA, Ferri OM. 1989. Diagnóstico y prevalencia de la dioctofimosis canina en Corrientes, Resistencia y zonas aledañas. Vet Arg 6: 604-607.
7. Osborne CA, Stevens JB, Hanlon GF. 1969. Dioctophyme renale in a dog. J Am Vet Assoc 155: 605-620.

8. Soulsby EJ. 1987. Parasitología y enfermedades parasitarias en los animales domésticos, Interamericana, México, p. 343-344.

9. Trigo Tavera FJ. 1998. Patología sistémica veterinaria, $3^{\circ}$ ed., McGraw-Hill, México, p. 33-83. 